\title{
Neural Networks and Regression Modeling of Eco- friendly Melting Furnace Parameters using Bio-fuels
}

\author{
Purshottam Kumar \\ Dayalbagh Educational Institute \\ Dayalbagh, Agra-282005, U.P., INDIA - 282110
}

\author{
Ranjit Singh \\ Dayalbagh Educational Institute \\ Dayalbagh, Agra-282005, U.P., INDIA - 282110
}

\begin{abstract}
Rotary furnaces apart from being pollution efficient can maintain the quality standards set by the present methods of casting. The rising demand for high quality castings necessitates that vast amount of manufacturing knowledge be incorporated in manufacturing systems. Rotary furnace involves several critical parameters like flame temperature, preheat air temperature, revolutions per minute of the furnace, excess air percentage, melting time, fuel consumption and melting rate of the molten metal which should be controlled throughout the melting process. A complex relationship exists between these manufacturing parameters and hence there is a need to develop models which can capture this complex interrelationship and enable fast computation. In this paper the applicability and the relative effectiveness of the artificial neural networks as function approximators for rotary furnace have been investigated. The results obtained by these models are found to correlate well with the experimental data. Results obtained by the regression modeling are also found correlating well with the experimental data. This indicates that NN models and regression models can very well be used to model this complex relationship amongst various parameters in an eco-friendly melting furnace.
\end{abstract}

\section{General Terms}

Regression modeling, Neural Network

\section{Keywords}

Rotary Furnace, Artificial Neural Networks (ANN), BackPropagation (BP), Levenberg - Marquardt (LM) Approximation, Regression modeling.

\section{INTRODUCTION}

The voluminous production of Flue gases by cast iron foundries damages the environment since it contains gases like $\mathrm{SO}_{2}, \mathrm{CO}_{2}, \mathrm{CO}, \mathrm{H}_{2} \mathrm{~S}$ which are poisonous. Almost all the foundries use coke fired cupolas for melting. However, melting by coke-fired cupola does not obey the environmental regulations. The problem of objections from environmentalists to $80 \%$ of the existing foundries is due to their exorbitant pollution emission level which has posed a serious threat to these foundries. The control on operation of foundries has been imposed by social organizations and by Honorable Supreme Court of India. In Agra, the city of foundries, the Honorable Supreme Court of India has totally banned the operation of Coke-fired Cupola. So, it has been essential to develop a substitute of coke as fuel in the foundries [1]. The Author had designed and developed a Rotary furnace of $200 \mathrm{~kg}$. capacity and conducted lots of experiments to evaluate the performance of the furnace with different parameters.
The Rotary Furnace is very simple melting unit consisting mainly of a drum of required size having a cone on each side lined with refractory, fire bricks or ramming mortar generally having alumina as a constituent. This Furnace drum is placed on rollers which may be locked when the furnace is not rotated and may slowly rotate about their central axis when the furnace is rotated (for homogeneous mixture of molten metal and proper heat transfer). The rollers are driven by a small electric motor. At one end of the drum, a suitable burner is placed with appropriate blower system and combustion gases exit from other end. This drum or horizontal cylinder is flanked by two conical portions on both sides. One of the cones accommodate the burner whereas from the other cone hot flue gasses exit. Charging of the iron for melting is also done from this side. The cone on one side can accommodate different types of burners using the pure Jatropha and blends of Jatropha oil with Diesel. The tap hole is located in the cylindrical wall halfway between the ends. This tap hole is used to take out the molten metal. During the melting of metal this tap hole is closed.

There are a number of variables controllable to varying degrees which affect the quality and composition of the outcoming molten metal. These variables, such as flame temperature, preheat air temperature, revolutions per minute, excess air percentage, melting time, fuel consumption and melting rate play significant role in determining the molten metal's properties and should be controlled throughout the melting process [2]. However, even an experienced operator may find it difficult to select the optimum input parameters which would yield ideal molten metal and often he may choose them by guessing which may not be effective and economical.

Several investigators have carried out studies and developed mathematical models concerning the problem of choosing the optimum input parameters. Levi [3] was the first person to develop a mathematical model between carbon content in the charge and that of the tapped metal in cupola operations. Davis and Decrop [4] concluded that blast temperature has significant control over metal temperature and hence on carbon pick up. Pehle [5] developed the first thermo chemical model for predicting cupola performance under various operating conditions. Artificial neural networks (ANN) are useful tools for prediction, function approximation and classification. It is well suited to extracting information from imprecise and non-linear data. Karunakar and Datta [6] used ANN to model cupola furnace parameters with about 5\% error. Regression techniques have a long history of use as forecasting tools in multiple disciplines. Regression models have the advantage of simple computation and easy implementation. Regression models are also used for decision 
making [7]. Vasin et al. [8] also developed practical crash prediction regression models for assessing the long-range safety impact of alternative freeway networks for urban areas.

\section{OBJECTIVE OF STUDY}

A Rotary Furnace was self-designed and developed at Foundry Shop, Faculty of Engineering, Dayalbagh Educational Institute (D.E.I), Dayalbagh, Agra, INDIA and experiments were conducted by taking the following input variables: 1) Percentage of Excess Air, 2) Flame Temperature, 3) Rotational Speed, 4) Melting Time, 5) Pre-heat Air Temperature, 6) Fuel Consumed for calculating the Melting Rate. And after conducting a number of experiments it has been observed that critical parameters affecting the Melting rate are Rotational speed of furnace dome, Melting time of metal and fuel consumed in melting the metals. So, only these three parameter observations are taken from 201 observations taken from 201 heats. Number of observation represented in table 1 and 2 are the representative observations from a bigger set of 201 observations. So the main aim of this study was to randomly selecting 18 heats and to verify the influence of these critical parameters on the Melting Rate by developing Neural Network and Regression models.

\section{METHODOLOGY}

\subsection{Experimental Setup and Data Collection}

In the experimentation, $200 \mathrm{~kg}$. of the charge is melted in the rotary furnace. A Circular burner is used for burning Jatropha oil with $50 \%$ blending with Diesel as fuel. Due to the heat transfer by conduction, when refractory material comes in contact with the molten charge, to have better heat transfer, the maximum time is given to refractory to be in contact with the charge. The quantity of fuel consumed is reduced in subsequent heats and normally it is found to be almost constant in third heat onwards.

Numbers of experiments were conducted at different percentage of excess air varying from $10 \%$ to $50 \%$ and amount of air preheat from $200^{\circ} \mathrm{C}$ to $400^{\circ} \mathrm{C}$ [9].

It was observed that it is difficult to achieve the rotation below 0.8 RPM from the fabricated rotary furnace. So, keeping this in view the experiments were carried out at rotational speed ranged from (0.8 - 2.0) RPM.

While conducting experiments it was observed that rate of melting varies with change of rotational speed. Charge of 200 $\mathrm{kg}$. when melted in the furnace at 2 RPM, took 45 minutes. The rate of melting (MR) was obtained

\section{$=0.266 \mathrm{MT}($ Metric Ton $) /$ Hour}

Under similar conditions, the total time taken for complete melting from third heat onwards was reduced to 35 minutes, when the rotational speed is reduced to 1 RPM. The rate of melting (MR) was obtained

\section{$=0.343 \mathrm{MT}($ Metric Ton $) /$ Hour}

From above it can be interpreted that the rate of melting is high at slower rotational speed. During experimentation it was observed that the fuel consumption varies with rotational speed, percentage of excess air and air pre-heat temperature. Charge of $200 \mathrm{~kg}$. when melted in the furnace at $2 \mathrm{RPM}$ with $20 \%$ excess air and $300^{\circ} \mathrm{C}$ air pre-heat, took 47 minutes and consumed 85 liters of LDO. The rate of fuel consumption obtained $=0.425$ Liters $/ \mathrm{Kg}$.

Under similar conditions, the fuel consumption for complete melting of charge at the rotational speed of 1 RPM with $20 \%$ excess air and $300^{\circ} \mathrm{C}$ air preheat was 81 liters. The rate of fuel consumption was obtained $=0.405$ Liters $/ \mathrm{Kg}$.

From the above discussion it can be interpreted that the rate of fuel consumption is high at higher rotational speed.

Large numbers of heats were taken from the rotary furnace with the variations of the above mentioned parameters and finally a set of 201 heats was obtained from the furnace. This data was used to train the artificial neural network and also for the regression modeling.

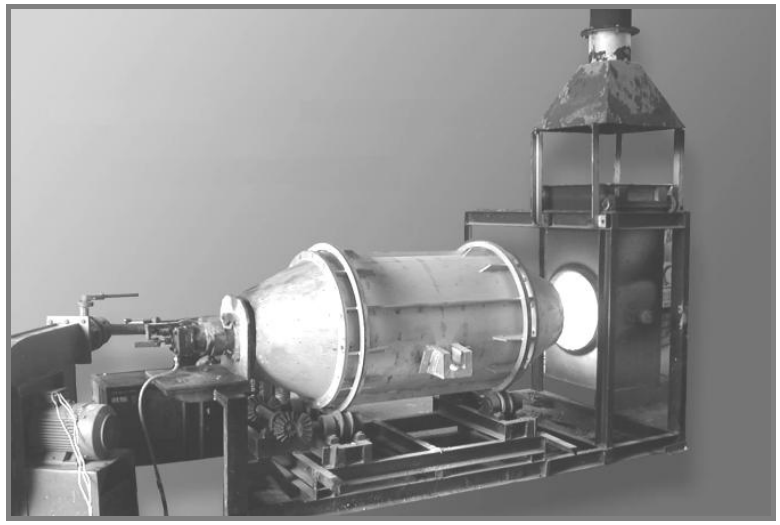

Fig 1: Designed and Developed Rotary Furnace at D.E.I., Dayalbagh

\subsection{Artificial Neural Network}

Artificial Neural Networks (ANNs) are massively parallel adaptive networks of simple nonlinear computing elements called neurons which are intended to abstract and model some of the functionalities of the human nervous system in an attempt to partially capture some of its computational strengths.

Artificial Neural Networks (ANNs) are currently gaining wide popularity in manufacturing field $[10,11]$. ANNs are proposed to represent the relationship between the operating conditions and the process-related variables because of their data driven approach i.e. they can capture and model extremely complex relationships even without the help of an explicitly stated mathematical model. This property of ANNs is extremely useful in situations where it is difficult to derive the mathematical model that links the various parameters.

\subsubsection{Back Propagation Neural Networks}

The Back Propagation (BP) neural network is a multiple layer network with one input layer, one output layer and some hidden layers between input and output layers [12]. Its learning procedure is based on gradient search with least sum squared optimality criterion. Calculation of the gradient is done by partial derivative of sum squared error with respect to weights. After the initial weights have been randomly specified and the input has been presented to the neural network, each neuron computed weighted sums of inputs from all neurons in the preceding layer are used as inputs to succeeding layers and final the networks weighted sum is calculated. The sums and activation (output) values for each neuron in each layer are propagated forward through to entire network to compute an actual output and error of each neuron in the output layer. The error for each neuron is computed as the difference between actual output and its corresponding target output, and then the partial derivative of sum-squared errors of all the neurons in the output layer is propagated back through the entire network and the weights are updated. In course of the BP learning, a gradient search procedure is used 
to find connection weights of the network, but it tends to trap itself into the local minima. The local minima may be avoided by adjusting value of the momentum. This algorithm can be expressed succinctly in the form of a pseudo-code as given below:

1. Pick a rate parameter $\mathrm{R}$

2. Until performance is satisfactory.

For each sample input

Compute the resulting output.

Compute $\beta$ for nodes in the output layer using

$\beta_{\mathrm{z}}=\mathrm{D}_{\mathrm{z}}-\mathrm{O}_{\mathrm{z}}$

Where D represents the desired output and $\mathrm{O}$ represents the actual output of the neuron

Compute $\beta$ for all other nodes using

$\beta_{\mathrm{j}}=\sum_{\mathrm{k}} \mathrm{W}_{\mathrm{j} \rightarrow \mathrm{k}} \mathrm{O}_{\mathrm{k}}\left(1-\mathrm{O}_{\mathrm{k}}\right) \beta_{\mathrm{k}}$

Compute weight changes for all weights using

$\Delta \mathrm{W}_{\mathrm{i} \rightarrow \mathrm{j}}=\mathrm{r} \mathrm{O}_{\mathrm{i}} \mathrm{O}_{\mathrm{j}}\left(1-\mathrm{O}_{\mathrm{j}}\right) \beta_{\mathrm{j}}$

Add up the weight changes for all sample inputs and change the weights.

\subsubsection{Levenberg - Marquardt (LM) \\ Approximation}

The standard BP algorithm suffers from the serious drawbacks of slow convergence and inability to avoid local minima Therefore, BP with Levenberg - Marquardt (LM) approximation is used in this work. LM learning rule uses an approximation of the Newton's method to get better performance [13]. This technique is relatively faster but requires more memory. The $\mathrm{LM}$ update rule is:

$\Delta \mathrm{W}=\left(\mathrm{J}^{\mathrm{T}} \mathrm{J}+\mu \mathrm{I}\right)^{-1} \mathrm{~J}^{\mathrm{T}} \mathrm{e}$

Where $\mathbf{J}$ is the Jacobean matrix of derivatives of each error to each weight, $\mu$ is a scalar and $\mathrm{e}$ is an error vector. If the scalar is very large, the above expression approximates the Gradient Descent method; while it is small the above expression becomes the Gauss - Newton method. The Gauss Newton method is faster and more accurate near error minima. Hence, the aim is to shift towards the Gauss - Newton as quickly as possible. The $\mu$ is decreased after each successful step and increased only when the step increases the error.

\subsubsection{Network Training and Development of \\ Model}

A two layer feed forward network with three input neurons, three neurons in the first hidden layer $\left(\mathrm{S}_{1}\right)$, two neurons in the second hidden layer $\left(\mathrm{S}_{2}\right)$, and one output neurons in the output layer is designed and trained with LM learning rule. The logarithm of sigmoid function is used in the first hidden layer, tangent of sigmoid in the second hidden layer and the output layer has pure linear neurons. The neural network architecture is shown in the figure 2 .

The input parameters are:

1. Rotational Speed (R.P.M)

2. Melting Time (min.)

3. Fuel Consumed (Liters)

Melting Rate is taken as single output parameter.

The training parameters are as follows:

Frequency of progress displays (in epochs) $=20$

Maximum number of epochs to train $=300$
Sum-squared error goal $=10-8$

Neurons in layer $1, \mathrm{~S} 1=3$

Neurons in layer 2, S2 $=2$

Number of epochs $=130$

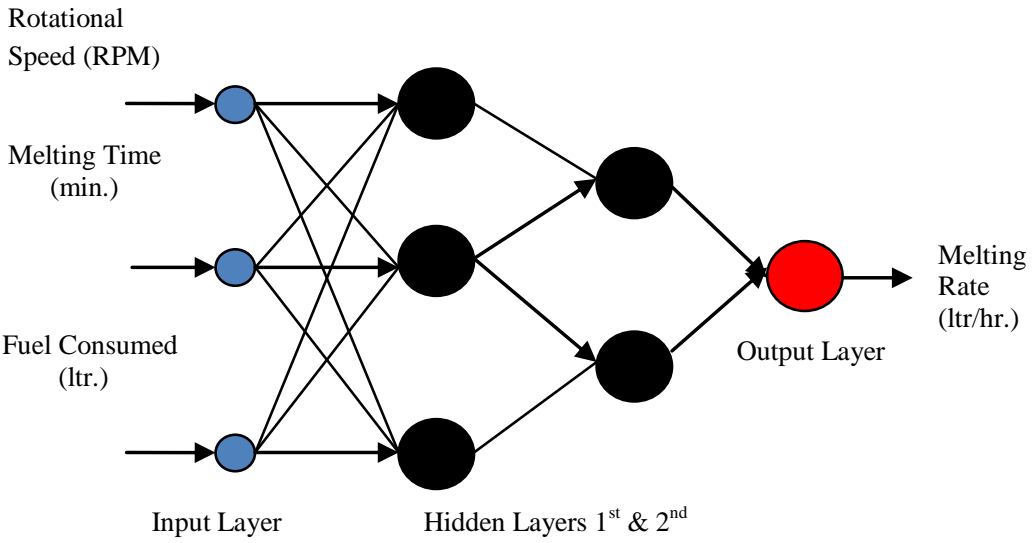

Fig 2: Proposed Neural Network Architecture

\subsection{Regression Modeling}

Captions Statistical methods such as cluster analysis, pattern recognition, design of experiments, factor analysis, and regression analysis are some of the statistical techniques which enable one to analyze the experimental data and build empirical models to obtain the most accurate representation of physical situations. In case of Rotary furnace which is designed and developed in Faculty of Engineering, D.E.I. numbers of heats were produced varying some of the critical parameters and output as melting rate was observed from the regressive experiments. In order to accurately model the melting rate in Rotary furnace one needs to determine the critical parameters affecting the melting rate. To keep the experiments manageable, major variables with their nominal values are selected.

The Critical input Parameters affecting the melting rate are:

1. Rotational Speed (in RPM)

2. Melting Time (in Minutes)

3. Fuel Consumed (in Liters)

Melting Rate is taken as single output Parameter.

Melting Rate (M), which is a function of Rotational Speed $(\mathrm{R})$, Melting Time (T) and Fuel Consumed $(\mathrm{F})$, is as follows:

$\mathrm{M}=\mathrm{C}_{0} \times \mathrm{R}^{\mathrm{C} 1} \times \mathrm{R}^{\mathrm{C} 2} \times \mathrm{R}^{\mathrm{C} 3}$

on taking logarithm of both the sides,

$\ln \mathrm{M}=\ln \mathrm{C}_{0}+\mathrm{C}_{1} \ln \mathrm{R}+\mathrm{C}_{2} \ln \mathrm{T}+\mathrm{C}_{3} \ln \mathrm{F}$

The regression model for this problem involves three variables; therefore their dependency relationship can be mathematically expressed as follows:

$Y=\beta_{0}+\beta_{1} X_{1}+\beta_{2} X_{2}+\beta_{3} X_{3}+\varepsilon$

which is a natural extension of the simple linear regression model.

In matrix notation, it can be written as:

$\mathrm{Y}=\mathrm{X} \beta+\varepsilon$

Data for developing multiple regression model is shown in Table 2. Response of Eighteen observations on model Y and on the three variables $X_{1}, X_{2}$ and $X_{3}$ can be written as follows: 


$$
\mathrm{Y}=\left[\begin{array}{l}
5.7291 \\
5.7817 \\
5.4806 \\
5.5215 \\
5.5215 \\
5.5215 \\
5.8663 \\
5.5215 \\
5.6791 \\
5.7038 \\
5.8091 \\
5.6791 \\
5.7817 \\
5.7038 \\
5.6315 \\
5.9269 \\
5.8373 \\
5.7038
\end{array}\right]
$$

$X=\left[\begin{array}{cccc}1 & 0.693147 & 3.663562 & 4.356709 \\ 1 & 0.693147 & 3.610918 & 4.369448 \\ 1 & 0.693147 & 3.912023 & 4.382027 \\ 1 & 0.470004 & 3.871201 & 4.454347 \\ 1 & 0.470004 & 3.871201 & 4.430817 \\ 1 & 0.470004 & 3.871201 & 4.442651 \\ 1 & 0.336472 & 3.526361 & 4.369448 \\ 1 & 0.336472 & 3.871201 & 4.430817 \\ 1 & 0.336472 & 3.713572 & 4.382027 \\ 1 & 0.182322 & 3.688879 & 4.394449 \\ 1 & 0.182322 & 3.583519 & 4.343805 \\ 1 & 0.182322 & 3.713572 & 4.369448 \\ 1 & 0 & 3.610918 & 4.369448 \\ 1 & 0 & 3.688879 & 4.369448 \\ 1 & 0 & 3.7612 & 4.394449 \\ 1 & -0.22314 & 3.465736 & 4.304065 \\ 1 & -0.22314 & 3.555348 & 4.330733 \\ 1 & -0.22314 & 3.688879 & 4.369448\end{array}\right]$

This estimates the model parameters $\left\{\beta_{0}, \beta_{1}, \beta_{2}\right.$ and $\left.\beta_{3}\right\}$. Now,

$\mathrm{C}_{0}=11963, \mathrm{C}_{1}=-0.000044367, \mathrm{C}_{2}=-0.99999, \mathrm{C}_{3}=0.00070192$ So, Melting Rate from equation (5) comes out to be as follows:

$\mathrm{M}=11963 \times \mathrm{R}^{-0.000044367} \times \mathrm{T}^{-0.99999} \times \mathrm{F}^{0.0007019}$

Values of $M$ estimated by multiple regression model is shown in Table 2.

Taking natural logarithm of equation (10) gives:

$\ln \mathrm{M}=\ln 11963-0.000044367 \ln \mathrm{R}-0.99999 \ln \mathrm{T}+$ $0.00070192 \ln \mathrm{F}$

\section{COMPARISON OF RESULTS}

Table 1: Comparison of the experimental values of output (actual melting rate) and ANN modeled melting rate

\begin{tabular}{|c|l|c|c|l|l|l|}
\hline S.No. & $\begin{array}{l}\text { Rotational } \\
\text { Speed } \\
(\text { RPM })\end{array}$ & $\begin{array}{c}\text { Melting } \\
\text { Time } \\
\text { (Minutes) }\end{array}$ & $\begin{array}{c}\text { Fuel } \\
\text { Consumed } \\
\text { (Liters) }\end{array}$ & $\begin{array}{c}\text { Melting Rate } \\
\text { (Liters/Hour) } \\
\text { Experimental }\end{array}$ & $\begin{array}{c}\text { Melting Rate } \\
\text { (Liters/Hour) } \\
\text { ANN model }\end{array}$ & $\begin{array}{l}\text { Percentage } \\
\text { Variation }\end{array}$ \\
\hline 1. & 2.0 & 39 & 78 & 307.692 & 307.68 & 0.004011 \\
\hline 2. & 2.0 & 37 & 79 & 324.324 & 324.3076 & 0.005171 \\
\hline 3. & 2.0 & 50 & 80 & 240 & 240.0018 & -0.00074 \\
\hline 4. & 1.6 & 48 & 86 & 250 & 250.0028 & -0.00114 \\
\hline 5. & 1.6 & 48 & 84 & 250 & 249.9967 & 0.001301 \\
\hline 6. & 1.6 & 48 & 85 & 250 & 250.0003 & -0.00012 \\
\hline 7. & 1.4 & 34 & 79 & 352.941 & 352.8833 & 0.016391 \\
\hline 8. & 1.4 & 48 & 84 & 250 & 250.0081 & -0.00324 \\
\hline 9. & 1.4 & 41 & 80 & 292.683 & 292.7295 & -0.01593 \\
\hline 10. & 1.2 & 40 & 81 & 300 & 300.0311 & -0.01038 \\
\hline 11. & 1.2 & 36 & 77 & 333.333 & 333.2917 & 0.012488 \\
\hline 12. & 1.2 & 41 & 79 & 292.683 & 292.696 & -0.00445 \\
\hline 13. & 1.0 & 37 & 79 & 324.324 & 324.2701 & 0.01673 \\
\hline 14. & 1.0 & 40 & 79 & 300 & 299.9873 & 0.004232 \\
\hline 15. & 1.0 & 43 & 81 & 279.07 & 279.0821 & -0.00441 \\
\hline 16. & 0.8 & 32 & 74 & 375 & 374.99 & 0.002677 \\
\hline 17. & 0.8 & 35 & 76 & 342.857 & 342.9214 & -0.01875 \\
\hline 18. & 0.8 & 40 & 79 & 300 & 299.9883 & 0.003907 \\
\hline
\end{tabular}


Table 2: Comparison of the experimental values of output (actual melting rate) and Regression modeled melting rate

\begin{tabular}{|c|c|c|c|c|c|c|}
\hline S.No. & $\begin{array}{l}\text { Rotational } \\
\text { Speed } \\
\text { (RPM) }\end{array}$ & $\begin{array}{l}\text { Melting } \\
\text { Time } \\
\text { (Minutes) }\end{array}$ & $\begin{array}{c}\text { Fuel } \\
\text { Consumed } \\
\text { (Liters) }\end{array}$ & $\begin{array}{l}\text { Melting Rate } \\
\text { (Liters/Hour) } \\
\text { Experimental }\end{array}$ & \begin{tabular}{|c|} 
Melting Rate \\
(Liters/Hour) \\
Regression \\
model
\end{tabular} & $\begin{array}{l}\text { Percentage } \\
\text { Variation }\end{array}$ \\
\hline 1. & 2.0 & 39 & 78 & 307.692 & 307.685 & 0.002415 \\
\hline 2. & 2.0 & 37 & 79 & 324.324 & 324.319 & 0.001574 \\
\hline 3. & 2.0 & 50 & 80 & 240 & 239.999 & 0.00039 \\
\hline 4. & 1.6 & 48 & 86 & 250 & 250.014 & -0.00564 \\
\hline 5. & 1.6 & 48 & 84 & 250 & 250.01 & -0.00398 \\
\hline 6. & 1.6 & 48 & 85 & 250 & 250.012 & -0.00481 \\
\hline 7. & 1.4 & 34 & 79 & 352.941 & 352.941 & 0.000076 \\
\hline 8. & 1.4 & 48 & 84 & 250 & 250.011 & -0.00458 \\
\hline 9. & 1.4 & 41 & 80 & 292.683 & 292.686 & -0.00099 \\
\hline 10. & 1.2 & 40 & 81 & 300 & 300.008 & -0.00253 \\
\hline 11. & 1.2 & 36 & 77 & 333.333 & 333.33 & 0.001135 \\
\hline 12. & 1.2 & 41 & 79 & 292.683 & 292.685 & -0.0008 \\
\hline 13. & 1.0 & 37 & 79 & 324.324 & 324.329 & -0.0015 \\
\hline 14. & 1.0 & 40 & 79 & 300 & 300.005 & -0.00158 \\
\hline 15. & 1.0 & 43 & 81 & 279.07 & 279.079 & -0.00341 \\
\hline 16. & 0.8 & 32 & 74 & 375 & 374.992 & 0.002243 \\
\hline 17. & 0.8 & 35 & 76 & 342.857 & 342.856 & 0.000281 \\
\hline 18. & 0.8 & 40 & 79 & 300 & 300.008 & -0.00257 \\
\hline & & & 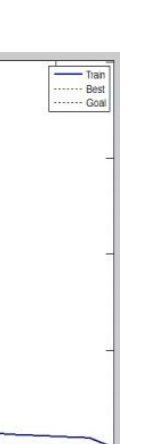 & {$\left[\begin{array}{c}0.02 \\
0.01 \\
0 \\
-0.01 \\
-0.02 \\
-0.03\end{array}\right]$} & Varia & tion of Percentage error \\
\hline$x^{\frac{1}{\infty}}+\frac{1}{40}$ & Troining & & & Fig 4: & $\begin{array}{r}\text { riation of Per } \\
\text { Regress }\end{array}$ & $\begin{array}{l}\text { centage Error with ANN and } \\
\text { sion Modeling }\end{array}$ \\
\hline $\begin{array}{l}\text { Fig 3: } \\
\text { Table } 1 \text { is representing the } \\
\text { and the estimated value b } \\
\text { is representing the experin } \\
\text { by Regression model. Th } \\
\text { Table } 1 \text { and 2, show that } \\
\text { have approximately same } \\
\text { experimentations. It was } \\
\text { parameters Rotational } \\
\text { consumed are the main fac } \\
\text { The training graph betwee } \\
\text { epochs is shown in Figu } \\
\text { variation in the percenta } \\
\text { modeling. And it shows } t \\
\text { error less than } 5 \% \text {. The re } \\
\text { as compared to the predict }\end{array}$ & $\begin{array}{l}\text { Training Gr } \\
\text { experimenta } \\
\text { the NN mo } \\
\text { ental value a } \\
\text { te percentag } \\
\text { both ANN } \\
\text { results as v } \\
\text { also obser } \\
\text { peed, Melti } \\
\text { tors which af } \\
\text { n sum square } \\
\text { re } 3 \text {. Figure } \\
\text { ge error by } \\
\text { hat both the } \\
\text { sults predicte } \\
\text { lon of Karun: }\end{array}$ & $\begin{array}{l}\text { ph } \\
\text { value of me } \\
\text { el. Similarly, } \\
\text { d the estimat } \\
\text { variations s } \\
\text { nd regression } \\
\text { as obtained } \\
\text { ed that, the } \\
g \text { Time, a } \\
\text { ect the Meltir } \\
\text { error and n } \\
4 \text { is represer } \\
\text { Regression as } \\
\text { nodels are gi } \\
\text { are with les } \\
\text { karan and Du }\end{array}$ & $\begin{array}{l}\text { ting rate } \\
\text { Table } 2 \\
\text { ed value } \\
\text { hown in } \\
\text { models } \\
\text { rom the } \\
\text { critical } \\
\text { ad Fuel } \\
\text { ig Rate. } \\
\text { imber of } \\
\text { ting the } \\
\text { id ANN } \\
\text { ving the } \\
\text { ser error } \\
\text { ta [6]. }\end{array}$ & $\begin{array}{l}\text { 5. CON } \\
\text { The neural } \\
\text { effectively } \\
\text { Speed, Mel } \\
\text { obtained us } \\
\text { Levenberg } \\
\text { network gi } \\
\text { experimenta } \\
\text { These perfo } \\
\text { tool for m } \\
\text { models ha } \\
\text { manufacturi } \\
\text { gives good } \\
\text { with less th } \\
\text { easily capt } \\
\text { process par: } \\
\text { manufacturi } \\
\text { avenues of } \\
\text { optimization } \\
\text { systems. }\end{array}$ & $\begin{array}{l}\text { CLUSION } \\
\text { network mode } \\
\text { stimate the m } \\
\text { ing time, and } \\
\text { ng most critical } \\
\text { Marquardt trai } \\
\text { e good estim } \\
\text { values with an } \\
\text { mance figures } \\
\text { deling and pre } \\
\text { e emerged as } \\
\text { g processes. Si } \\
\text { estimation and } \\
\text { in } 5 \% \text { error. Re } \\
\text { re the intricat } \\
\text { meters and can } \\
\text { ig environment } \\
\text { parameter esti } \\
\text { and online co }\end{array}$ & $\begin{array}{l}\text { els developed in this paper can } \\
\text { nelting rate based on Rotational } \\
\text { Fuel consumption. The results } \\
\text { l input parameters of furnace and } \\
\text { ining for back propagation neural } \\
\text { mation and are validated with } \\
\text { error much lesser than } 5 \% \text { error. } \\
\text { suggest that ANN is a powerful } \\
\text { edictive applications. The ANN } \\
\text { s a new alterative to model } \\
\text { imilarly Regression modeling also } \\
\text { validated with experimental data } \\
\text { esults show that these techniques } \\
\text { te relationship between various } \\
\text { be readily integrated into existing } \\
\text { t. These techniques open new } \\
\text { imation, function approximation, } \\
\text { ontrol of complex manufacturing }\end{array}$ \\
\hline
\end{tabular}




\section{REFERENCES}

[1] Singh R., Patvardhan C., Jain R. K. and A. Kumar, (2000). "Economic Justification of Coke-less Cupola for Pollution Free Casting in Indian Environment with Special Reference to Agra" Indian Foundry Journal, Vol. 46, No. 8, pp. 18-27.

[2] Singh R., Radha Krishna M., Patvardhan C. and Rana G. P., (2006). "Rotary Furnace: Effect of Rotational Speed on Rate of Melting, Fuel Consumption and Pollution", Indian foundry Journal, Vol. 52, No. 2, pp. 38-40.

[3] Levi W. W., (1947). "Variables affecting Carbon Control in Cupola Operation", Transactions of APS, Vol.55, pp. 626-632.

[4] Davis F. and M. Decrop, (1958). "Influence of Blast Input, Coke Size and Melting Coke Ratios on Cupola Performance", Foundry Trade Journal, pp. 319-325.

[5] Pehle R. D., (1963). "Thermo-chemical Model of Computer Prediction of Cupola Performance", AFS Transactions, Vol. 71, pp. 580-587.

[6] Karunakar, D. B. and G. L. Datta, (2002). "Modeling of cupola furnace parameters using Artificial Neural Networks", Indian Foundry Journal, Vol. 48, pp. 29-39.

[7] Andrew Gelman, Matt Stevens, and Valerie Chan, 2003 "Regression Modeling and Meta-Analysis for Decision Making: A Cost-Benefit Analysis of Incentives in Telephone Surveys," 1, pp. 1-13.
[8] Vasin Kiattikomo, Arun Chatterjee, Joseph E. Hummer, and Mary Sue Younger, 2008 "Planning Level Regression Models for Crash Prediction on Interchange and Non-Interchange Segments of Urban Freeways,' Journal of Transportation Engineering, 134 (3), pp.

[9] Singh R., Patvardhan C., Jain R. K. and A. Kumar, (2000). "Effect of Air - Preheating and Excess Air on the Performance of LDO Fired Rotary Furnace" Indian Foundry Journal, Vol. 46, No. 11, pp. 26-32.

[10] Hans Raj K., Sharma R. S., Setia R., Upadhyay V. and Alok K. Verma, (2006). "Modeling of Micro End Milling Operations with Artificial Neural Network Models", International Journal of Agile Manufacturing, Vol. 6, pp. 99-103.

[11] Hans Raj K., Sharma R. S., Srivastava S. and C. Patvardhan, (2000). "Modeling of Manufacturing Processes with ANN for Intelligent Manufacturing", International Journal of Machine Tools \& Manufacture, Vol. 40, pp. 851-868.

[12] Fausett L., (1994). "Fundamentals of Neural Networks", Prentice Hall, Eaglewood Cliffs, NJ.

[13] More, J. J., (1977). "The Levenberg - Maquardt Algorithm: Implementation and theory, Numerical Analysis", G. A. Watson (Ed.), Lecture Notes in Mathematics, Springer Verlag, Vol. 630, pp.105-116. 